\title{
OS IMPACTOS DO PIBID DE EDUCAÇÃO FÍSICA/ UNISINOS NA FORMAÇÃO DE DOCENTES
}

\author{
Rafael de Mello de Lima$^{1}$, Ednaldo da Silva Pereira Filho
}

\begin{abstract}
Resumo: O presente estudo teve como objetivo interpretar os impactos do PIBID (Programa Institucional de Bolsas de Iniciação à Docência) do curso de Educação Física da Universidade do Vale do Rio dos Sinos (UNISINOS) na formação de docentes. Trata-se de uma pesquisa de caráter exploratório, de metodologia mista com o uso de questionário eletrônico, entrevista individual e grupo de discussão com ex-bolsistas que participaram de, no mínimo, dois anos do Programa. Como resultados, através de descrição de frequência em gráficos e análise de conteúdo com as representações sociais, se verificou que o PIBID oportuniza aos bolsistas a experiência no contexto escolar como eixo central da formação docente; colabora com o planejamento coletivo e diálogos pedagógicos; antecipa o choque de realidade de uma forma mais confortável, pois há uma interação entre bolsistas, professor titular e Coordenador do Ensino Superior; aumento da autoconfiança; desinibição em falar em público; possibilita a contextualização da escola; causa reflexões constantes sobre o ensinar; permite a articulação teoria e prática; ocasiona experiências não só profissionais, mas também para a vida pós PIBID.
\end{abstract}

Palavras-chave: PIBID. Formação Docente. Representações Sociais.

\section{THE IMPACTS OF THE PIBID OF PHYSICAL EDUCATION/UNISINOS IN THE TEACHER FORMATION}

\begin{abstract}
The current study had as objetive to interpret the impacts of PIBID (Programa Institucional de Bolsas de Iniciação à Docência) of the class of Physical Education of the Universidade do Vale do Rio dos Sinos (UNISINOS) in the theachers formation. It is about an exploratory character search, mixed methodology with the use of an eletronic questionary, individual interview and a discussion group with former scholarship holders that participated of, at least, two years in the Program. As a results, through a frequency description in graphics and content analysis with the social representations, it has been found that the PIBID gives the opportunity to the former scholarship holders to have an experience in the scholar context as central axis of the theacher formation; collaborate with the collective planning and pedagogical dialogue; anticipate the reallity shock in a more comfortable way, as there is an interaction between scholarship holders, titular teacher and Coordinator of Higher Education; increased self-
\end{abstract}

1 Graduação em Licenciatura em Educação Física pela Universidade do Vale do Rio dos Sinos. E-mail: rafaeldemellodelima@gmail.com

2 Doutor em Ciências Sociais. Coordenador do Curso de Educação Física Licenciatura da Universidade do Vale do Rio dos Sinos. E-mail: ednaldo@unisinos.br 
confidence; disinhibition speaking in public; allows the contextualization of the school; causes constant reflections about teaching; makes it possible to joint theory and practice; brings not only professional experiences, but also life after PIBID.

Keywords: PIBID. Teacher Formation. Social Representations.

\section{INTRODUÇÃO}

Tendo em vista a permanente e sempre contemporânea importância política, social e cultural da formação docente, e a paradoxal desvalorização profissional no país expressa também na baixa proporção de formados em relação aos ingressantes no curso de licenciatura, surge a necessidade de interpretar os impactos do PIBID (Programa Institucional de Bolsa de Iniciação à Docência), na formação de docentes. Uma possibilidade concreta de vivência escolar enquanto formando em licenciatura é o PIBID, política pública nacional criada pelo MEC e existente, desde 2010, e que tenta consolidar a experiência de acadêmicos em ambientes escolares. Por outro lado, há uma conjuntura mundial desfavorável que parece desautorizar o investimento e incremento de políticas públicas.

Segundo dados do INEP (2017) o Brasil conta com 2,2 milhões de docentes atuantes e distribuídos em cerca de 186 mil escolas de Educação Básica. Diante desse grande número de profissionais, se fazem necessárias outras contribuições aos estudos de Berkembrock (2015), Gatti et. al. (2014), Carvalho e Queires (2016), Rausch e Frantz (2013), Carvalho (2016) para ampliar as interpretações sobre os impactos do PIBID na formação docente.

Em 2007 foi criado o Plano de Desenvolvimento da Educação (PDE) que visa produzir melhorias até 2022 com 20 metas que citam o acesso e permanência na educação, busca da igualdade educacional, formação docente e a cidadania. Um dos alicerces para uma educação de qualidade é a construção de profissionais motivados e comprometidos com os alunos da Educação Básica. Através de salários atrativos, planos de carreira, condições de trabalho e processos de formação inicial e continuada - onde se encaixa o PIBID - é possível melhorar a qualidade da Educação Básica pública (MEC, 2014).

Berkembrock (2015) salienta que o PIBID é capaz de unir dois níveis de ensino, o Ensino Superior e a Educação Básica, sendo assim capaz de promover melhorias em questões sociais, econômicas e educacionais tanto para bolsistas, universidade, escola e para professores através de tarefas multidisciplinares e uma formação continuada aos docentes.

O presente estudo está estruturado de forma que ocorra uma caracterização do PIBID e contextualização da formação de docentes. Na sequência, há o referencial teórico com a base dos dados da pesquisa e autores que serão utilizados na discussão de resultados. Na metodologia está explicitado o passo-a-passo dos elementos teórico- 
metodológicos, como ocorreu a coleta de dados, a análise de resultados e, por fim, os procedimentos éticos da pesquisa. Em seguida, há a discussão de resultados divididos em categorias de análise que relacionam o perfil dos ex-bolsistas e os impactos do PIBID com a trajetória, teoria/prática, alunos, planejamento, contexto escolar e vida pós PIBID, no sentido de abordar informações colhidas nas entrevistas, no grupo de discussão e no questionário eletrônico juntamente com os autores de estudos sobre o PIBID e formação docente.

\section{FUNDAMENTAÇÃO TEÓRICA}

Para a composição do referencial teórico a seguir foram feitas pesquisas em bases de dados eletrônicos, na busca das palavras chaves: "PIBID", 'Educação Física escolar", "docente", "avaliação" e "educação básica". Dos estudos encontrados e citados acima, foram adotados como eixo principal de análise e discussão o trabalho de Gatti et. al. (2014) e os dados do INEP (2017) e CAPES (2008), além de outros autores utilizados durante a fundamentação teórica que são pensadores de relevância para a discussão da formação docente na educação brasileira.

\subsection{Caracterizações do PIBID}

O termo PIBID é uma sigla para Programa de Institucional de Bolsa de Iniciação à Docência que tem como iniciativa aperfeiçoar e valorizar a formação de professores para atuar na educação básica. O Programa foi criado pelo Centro de Aperfeiçoamento Pessoal de Nível Superior (CAPES) em conjunto com o Ministério da Educação (MEC) e do Fundo Nacional de Desenvolvimento da Educação (FNDE), visando aprimorar a formação de docentes. No ano de 2010, o Programa é instituído com o Decreto $\mathrm{n}^{\circ} 7219$ com objetivo de incentivar a formação de professores para atuar na educação básica pública que estão matriculados em cursos de licenciatura (BRASIL, 2010).

Em uma avaliação do PIBID feita por Gatti et. al. (2014), o Programa, contava com aproximadamente 90.000 bolsistas no ano em todo o país atuando em cinco mil escolas de educação básica e com 284 IES participantes do mesmo. É de suma importância descrever alguns impactos do PIBID na política de formação de professores. Os autores ainda destacam que o programa não é apenas um auxiliador aos acadêmicos em licenciatura, mas também um rearticulador de docentes formados, um viabilizador de novas ideias, condutas e repensamento educacional das escolas e uma vasta possibilidade de novas pesquisas e oportunidades para os professores e coordenadores das IES.

Gatti et. al. (2014) salientam que o PIBID surgiu como proposta fomentar a formação docente com qualidade e aproximar o acadêmico com o contexto da atuação do professor. Além disso, há uma defasagem no número de professores no Brasil, pois 
Ruiz (2008) já destacava que deveria haver um incremento geral no magistério, em torno de, 250 mil professores no ensino médio e de 480 mil no ensino fundamental.

A ação do bolsista do PIBID ocorre junto com outros bolsistas do Programa, com o professor titular da escola de sua mesma área de atuação durante o horário letivo e dentro do contexto escolar, além de reuniões com professores do Ensino Superior. O PIBID tem, em síntese, como objetivos: a) incentivar a formação de docentes; b) valorizar o magistério; c) integrar educação superior e educação básica; d) inserir licenciandos no cotidiano das escolas; e) mobilizar professores e torna-los protagonistas na formação inicial e f) contribuir para a articulação entre teoria e prática (CAPES, 2008).

\subsection{Contextualização da formação de docentes}

Dentre os 2,2 milhões de docentes atuantes, segundo dados do INEP (2017), $84,3 \%$ trabalham em escolas localizadas na zona urbana, $12,9 \%$ na zona rural e apenas $2,8 \%$ atuam tanto na zona urbana como na zona rural. Cerca de $77,5 \%$ dos docentes atuantes na Educação Básica no Brasil possuem nível superior completo e destes, 90\% com graduação no curso de licenciatura. A maioria dos professores atua em uma única escola $(78,3 \%)$ e o restante $(21,7 \%)$ atuam em duas escolas ou mais (INEP, 2017). Mesmo sendo números significativos, não há ainda o cumprimento com os preceitos da LDB (Lei de Diretrizes e Bases) que previa 100\% dos professores com formação superior. Como citado no art. no 62 da LDB lei no 9394/96:

\footnotetext{
A formação de docentes para atuar na educação básica far-se-á em nível superior, em curso de licenciatura, de graduação plena, em universidades e institutos superiores de educação, admitida, como formação mínima para o exercício do magistério na educação infantil e nas quatro primeiras séries do ensino fundamental, a oferecida em nível médio, na modalidade normal. (BRASIL, 1996)
}

Ruiz (2008) salienta que entre os anos 1990 e 2005 formaram-se cerca de 130 mil profissionais em Educação Física aptos a atuarem em ambiente escolar. $\mathrm{O}$ autor salienta ainda que a Educação Física é o componente curricular que mais possui professores formados, algo que vai ao encontro dos dados do INEP (2017) ao salientar que no ensino fundamental dos anos iniciais do ensino fundamental ( $1^{\circ}$ ao $5^{\circ}$ ano) 68,8\% dos professores de Educação Física possuem curso de graduação no Ensino Superior de licenciatura em Educação Física, mas não vai ao encontro às séries finais do Ensino Fundamental (63,4\%), Ensino Médio (77,4\%), onde a Educação Física não é o componente curricular que mais possui professores com formação pela legislação vigente. 


\section{METODOLOGIA}

Na sequência há a exposição do passo a passo de como ocorreu o presente estudo, divididos em Fundamentação Teórico-Metodológica, procedimentos da coleta de dados, análise dos resultados e procedimentos Éticos da pesquisa.

\subsection{Fundamentação Metodológica}

A pesquisa realizada foi de natureza quanti-qualitativa que, segundo Creswell (2007) é caracterizada pela existência de dados numéricos e estatísticos juntamente coletados com dados textuais e audiovisuais, formando assim um método misto. Para Santos (2009) uma pesquisa de método misto possibilita uma maior compreensão de fenômenos sociais devido aos múltiplos aspectos expostos na coleta de dados.

Essa investigação foi um estudo de caso institucional - UNISINOS - que segundo Gaya (2008) refere-se a uma análise organizacional particular em um determinado espaço de tempo, no caso ex-bolsistas participantes do PIBID e suas relações com o programa institucional.

\subsection{Procedimentos da Coleta de Dados}

A amostra do presente estudo é não probabilística, por tipicidade e pode ser caracterizado como um enfoque multimétodo (BAUER; GASKELL, 2005), pois teve como instrumento de coleta de dados o questionário eletrônico, uma entrevista individual e uma discussão em grupo. Com isso, é possível aumentar a densidade da pesquisa diante da triangulação de instrumentos de coleta de dados.

Era de suma importância que os ex-bolsistas participantes da pesquisa estivessem atuando no ambiente escolar para a continuidade da pesquisa, pois o critério de inclusão/exclusão adotado pelo pesquisador foi: a) participação de no mínimo dois anos pelo PIBID e b) formação em Licenciatura em Educação Física pela UNISINOS (para o envio do questionário eletrônico); c) atuação em ambiente escolar (para o grupo de discussão e entrevista individual). Inicialmente foi enviado aos 38 ex-pibidianos que se encaixaram no critério de dois anos ou mais de participação no PIBID UNISINOS, de um questionário eletrônico por e-mail baseado em Silva (2012) para contextualizar a situação dos ex-bolsistas e coletar informações pessoais. O retorno obtido foi de 15 bolsistas (40\%), o que é satisfatório sabendo que segundo Markoni e Lakatos (2003) a média de retorno de questionários eletrônicos é de 25\%. Após as respostas do questionário eletrônico, foi realizado um grupo de discussão, utilizando-se os critérios "b" e "c" onde através do diálogo do encontro foi possível identificar nas representações sociais os impactos do PIBID na formação dos mesmos como docentes.

O questionário aplicado foi adaptado de Silva (2012) com a inserção do perfil dos ex-bolsistas do Programa. A grande facilidade do questionário eletrônico foi o envio 
coletivo sem deslocamento e monitoramento do mesmo, porém como dificuldade principal houve a falta de resposta e contato por parte de alguns.

A entrevista individual e o grupo de discussão envolveram temáticas de discussões relevantes ao grupo sobre representações sociais relacionadas com o PIBID e a formação docente. $\mathrm{O}$ grupo de discussão contou com três participantes. Houve também uma entrevista individual com uma professora que durou cerca de 40 minutos e o grupo de discussão teve uma hora de duração. $\mathrm{O}$ grande empecilho dessa parte do trabalho foi incompatibilidade de horários para a realização de um grupo de discussão. Uma exbolsista se disponibilizou em participar do trabalho, porém seu horário disponível não entrou em comum acordo com os demais e por uma questão ética dos pesquisadores em valorizarem a participação voluntária dos colaboradores, houve a adoção de uma entrevista individual, o que enriqueceu mais ainda o presente estudo.

\subsection{Procedimentos da Análise de Resultados}

Por ser uma pesquisa de caráter misto se privilegiou os dados quantitativos do questionário para fazer a descrição de frequência, enquanto para as informações qualitativas, a análise de conteúdo se valeu das representações sociais, que pode ser definidas como fenômenos representativos que ocorre em um grupo específico (bolsistas) que passaram por contextos parecidos (PIBID) e que de certa forma possui uma fluidez e troca de comunicações e interações (MOSCOVICI, 1978). Segundo Machado (2008) o uso de representações sociais na área da educação vem crescendo nas pesquisas nos últimos anos.

A análise de resultados foi feita a partir das respostas dos bolsistas através dos registros descritos no questionário eletrônico e do áudio da entrevista e do grupo de discussão, a fim de constituir uma correlação com os objetivos do Programa, levando em consideração proximidades e distancias entre eles. Houve uma "conversa" com as ideias de autores relacionados à prática da docência e do PIBID, tais como: Gatti et. al. (2014), Nóvoa. (1995), Tardif (2002) e Freire (2002).

Para Bardin (1977), a análise de conteúdo inicia-se na transcrição da entrevista através de uma leitura das falas. Por meio da divisão das categorias de análises, a préanálise (o que será analisado) foi composta por coleta de dados bibliográficos sobre como estão atualmente os indícios de formação docente e a relação da política pública do PIBID no mesmo; na exploração do material (análise de dados coletados) foi feita a escuta, transcrição e recorte das falas do grupo de discussão onde salientam - através de grifos - aspectos sobre os objetivos do PIBID perante sua formação docente e, por fim, no tratamento de resultados (interpretações), a "conversa" com os autores renomados sobre a formação docente através das falas dos colaboradores. 


\subsection{Procedimentos Éticos da Pesquisa}

O projeto foi submetido ao Comitê de Ética e Pesquisa da UNISINOS (CEP-UNISINOS), e aprovado pelo mesmo em maio de 2017 com o CAAE: 67781717.4.0000.5344. Foi feita a entrega do Termo de Consentimento Livre e Esclarecido aos participantes da pesquisa e a carta de Anuência ao coordenador institucional do PIBID da UNISINOS solicitando a autorização de consultas de cadastramento dos bolsistas no programa.

\section{RESULTADOS E DISCUSSÃO}

Nesta seção do trabalho serão feitas as discussões através dos resultados obtidos pelo questionário adaptado de Silva (2012), pela entrevista individual e pelo grupo de discussão. As categorias de análises, decorrentes da coleta de dados, foram: perfil dos ex-bolsistas estudantes de licenciatura, início da trajetória no PIBID, relação teoria/ prática, relação dos ex-bolsistas com os alunos da Educação Básica, planejamento e atuação, contexto escolar e vida pós PIBID.

\subsection{Perfis dos ex-bolsistas PIBID/UNISINOS}

O grupo de ex-bolsistas (quinze) possuem idades entre 22 e 36 anos, formados por dez mulheres (66\%) e cinco homens (33\%), sendo a maior parte de etnia formada por brancos (60\%), pardos e negros (33\%), e indígenas (6,7\%). Nesse sentido, no PIBID de Educação Física da UNISINOS existem evidências de uma diversidade étnico-racial maior até que a do Estado do Rio Grande do Sul que, segundo dados do IBGE (2010), $17 \%$ da população gaúcha é formada por negros e pardos, valor esse que é inferior ao comparado com o achado do presente estudo. Segundo estes mesmos dados do IBGE (2010), os indígenas no Rio Grande do Sul representam certa de 0,3 \% da população.

Dos 15 ex-bolsistas do PIBID, apenas quatro (26\%) estão atuando em ambiente escolar, sendo dois professores, um estagiário e um da coordenação da Educação Integrada, divididos em rede Pública Municipal (3) e rede Privada (1). Entre as respostas dos 11 ex-bolsistas que não estão atuando em ambiente escolar, a maior justificativa foi a de que não há oportunidades ou emprego na área.

\subsection{Início da trajetória no PIBID}

A maior motivação para entrar no PIBID para a maioria dos ex-bolsistas (13) que responderam o questionário eletrônico foi o interesse em atuar na realidade escolar e por ser uma nova experiência acadêmica (11 ex-bolsistas), o que vai ao encontro ao estudo de Silva (2012) que analisou essas duas alternativas como as mais recorrentes no questionamento. 
No grupo de discussão, houve dois colaboradores que citaram o PIBID como uma ferramenta de experiência no contexto escolar: 'Eu entrei no PIBID mais é pra ter uma experiência na área... " (transcrição da fala do Colaborador 2) e outro diz: "...tipo assim quando o colaborador 2 fala que é pelo motivo de experiência também é né..." (transcrição da fala do Colaborador 1).

Durante a entrevista, foi salientado o motivo de entrar no Programa: "eu busquei o PIBID principalmente por não ter nenhuma experiência na questão docente" (transcrição da fala do Colaborador 4)

Para Gómez (1995) o currículo acadêmico dos docentes deve ter a experiência no contexto escolar como o eixo central da formação dos mesmos, demonstrando assim a importância da vivência no cotidiano escolar durante o Ensino Superior, prática essa que o PIBID possibilita ao bolsista.

\subsection{Relação teoria e prática}

Muitos autores defendem uma teoria unida com a prática (FREIRE e SHOR, 1986; TARDIF, 2002; GATTI et al, 2014; NÓVOA, 1995) e um dos objetivos do PIBID é articular teoria e prática.

$\mathrm{Na}$ entrevista individual, é possível verificar que o colaborador na tentativa de explicar a relação entre teoria e prática termina por criar - paradoxalmente - uma dicotomia entre teoria e prática quando argumenta que teve uma boa base teórica advinda da UNISINOS, mas que a prática do PIBID tem um algo a mais no sentido de contextualização da escola:

'... a teoria ela ajuda muito ela nos dá a base só que é a prática que vai nos trazer o dia dia mesmo o que que vai ser" (Colaborador 4, grifo dos pesquisadores).

'... a teoria é importante embasar como fazer mas a prática do PIBID acho que é que a gente deveria ter mais acho que até a nível da instituição a UNISINOS, as universidades deveriam ter algum projeto pra gente entrar na realidade escolar mesmo" (transcrição da fala do Colaborador 4, grifo dos pesquisadores).

Durante o grupo de discussão, pode-se analisar através da fala de um colaborador o fato de que a teoria não é dissociada da prática, como na fala seguinte: "não existe teoria sem prática e prática sem teoria" (transcrição do Colaborador 3).

Um dos objetivos do PIBID é possibilitar a integração entre teoria e prática (CAPES, 2008) e na fala durante o grupo de discussão que vai ao encontro a Freire e Shor (1986) que cita que uma teoria unificada com a prática possibilita a "práxis".

Para 93\% (14) dos ex-bolsistas do questionário eletrônico, o PIBID auxiliou a compreender melhor as disciplinas pedagógicas do curso de Licenciatura em Educação 
Física pela UNISINOS, e em todas as respostas a relação teoria/prática estão presentes. Exemplos:

"A teoria passou a ser além da teoria e pude compreender na prática o que tudo aquilo de fato queria me dizer." (Colaborador 6, grifos dos pesquisadores).

"Associar a prática com a teoria foi muito importante durante a minha experiência no PIBID. "(Colaborador 7, grifo dos pesquisadores).

"Acredito que, com o PIBID e, principalmente, com a valorosa contribuição e orientação dos coordenadores da época, [...] pude compreender e aproveitar mais as disciplinas curriculares, onde mudei minha visão, procurando fazer as que não tinha tanto conhecimento e habilidade (aprender para ensinar futuramente). Além disso, as disciplinas pedagógicas das licenciaturas, também passei a valorizar mais e perceber o quanto podem agregar conhecimento para escritas de trabalhos e para a prática diária nas escolas". (Colaborador 8, grifos dos pesquisadores).

"Acredito que tenha ajudado a ter conhecimento mais abrangente do que as disciplinas apresentam como ambiente escolar, ou ter perspectiva de tudo aquilo não era como foi dito, que na escola iria encontrar diferente." (Colaborador 9, grifo dos pesquisadores).

Os saberes dos professores têm relação direta com aspectos de identidade, experiência, histórico profissional e com o ambiente escolar - esse último formado por alunos, escola, direção, funcionários e organização. É fundamental para a construção do docente que o mesmo consiga relacionar e refletir sobre saberes profissionais e experiências profissionais, uma vez que são entrelaçados (TARDIF, 2002).

\subsection{Relacionamentos dos ex-bolsistas do PIBID com alunos da Educação Básica}

Nas respostas obtidas no questionário eletrônico, a grande maioria (80\%) dos ex-bolsistas citaram que os alunos da Educação Básica das turmas em que atuavam, tratava-os como professor, o que não vai ao encontro com Silva (2012) que analisou o fato de que a maioria dos alunos viam os bolsistas do PIBID como alguém mais próximo, mas não como um docente.

Durante a entrevista, foi possível verificar ligações das falas encontradas no questionário eletrônico: “...confiando na gente questões deles pessoas e tudo, mas por eles terem essa visão como a gente não era professor, com a visão de que a idade é mais próxima então a gente fazia atividades diferentes, divertidas com eles então isso aproximava mais" (transcrição Colaborador 4).

Para Freire e Shor (1986) é através do diálogo em que há a possibilidade do aluno e do cidadão construir sua própria criticidade e conhecimento, tendo assim liberdade e autonomia para refletir sobre o que é certo e o que é errado e procurar modificar a 
atualidade, como na fala: “... Propor ideias sem medo, lidar com grande grupo de pessoas administrando aulas e planejar aulas.” (Colaborador 12, grifo dos pesquisadores).

'As culturas corporais de movimento é o exemplo principal, pois é o norte que guia o meu trabalho, procurando partir do interesse do aluno e me motivando a sempre continuar estudando. Além disso, sigo escrevendo trabalhos para seminários de educação, o que aprendi em grande parte no PIBID. "(Colaborador 13, grifos dos pesquisadores).

Para Cunha (1998), o docente precisa ser um pesquisador que ensina com a pesquisa e que pesquisa o que ensina, sempre se atualizando e ouvindo o aluno, possibilitando assim o estímulo de participação não só do professor, mas também do aluno, em que ambos estejam motivados aos estudos.

A ex-bolsista cita mudanças através da sua experiência no PIBID quanto ao presente do seu ambiente profissional como docente e diz: “...hoje procuro ter uma postura assim, mas um pouco mais por eu ser a única professora ali eles precisam saber que é a mim que eles têm que se reportar e falar tudo..." (transcrição Colaborador 4, grifo dos pesquisadores).

Nesse trecho há uma demonstração de que a experiência que a colaboradora teve durante o PIBID possibilitou a recriação sua conduta diante de seu profissionalismo na carreira como professora que vai ao encontro de García (1995) ao citar que a reflexão é o eixo central do professor e a mesma divide-se em técnica (ações durante a aula), prática (futuro e passado; erros e acertos) e crítica (social, cultural e ideológica). $\mathrm{Na}$ fala da entrevistada, pode-se identificar uma reflexão pratica que segundo o autor, é uma espécie de ponte entre o passado e o futuro onde há um pensamento sobre erros e acertos, procurando sempre o aprimoramento na tomada de decisões durante as aulas.

Durante a realização do grupo de discussão, alguns aspectos sobre a interação entre ex-bolsistas e alunos de forma a criar laços de amizade foram citados: '... a relação com eles foi uma relação muito boa". (Transcrição da fala do Colaborador 1). Outro diz: '... jogava futsal, vôlei com eles o que tina na aula a gente participava daí foi onde a gente criou um laço de amizade com os alunos",'... ai de ti não vir na nossa formatura..." (Transcrição da fala do Colaborador 2) e outro: '...também criei laços". (Transcrição da fala do Colaborador 3).

Segundo Schön (1995) o professor que ouve o aluno conflita com o ambiente escolar, pois para o autor, há uma burocracia escolar que dita o saber escolar e não o saber do aluno, mas para ouvi-lo há a necessidade de diálogo, confiança e amizade, adjetivos que o PIBID proporcionou para os bolsistas segundo a fala dos mesmos e esse diálogo pode ir ao encontro de Freire (2002) ao citar que ensinar exige escutar, no sentido de que uma fala com o aluno pode desenvolver uma criticidade no discurso do docente. Não há um ensino sem diálogo, sem pensar no contexto que o aluno vive. É necessário conhecer o discente, o meio que o mesmo está inserido e isso só é capaz com um laço de amizade entre o professor e o aluno. 


\subsection{Planejamento e atuação dos bolsistas e supervisor no PIBID}

Diante da forma de atuação durante as atividades do PIBID, via questionário eletrônico, $60 \%$ (8) dos ex-bolsistas salientaram que algumas atividades eram feitas em grupo e outras de forma individual e que gostavam dessa distribuição. Em comparação com os achados de Silva (2012), salientando que os bolsistas gostam dessa divisão de tarefas com momentos em grupo e individuais.

Durante o grupo de discussão, houve manifestações positivas sobre o planejamento coletivo: "...alguns tinham experiências em determinada área e a gente tentava se juntar para cada um passar um pouquinho essa experiência tipo na dança que só duas tinham essa experiência e a gente sentou, conversou e realizou o planejamento" (transcrição Colaborador 2, grifo dos pesquisadores). Outro diz: '...foi algo bem interessante assim pensar o planejamento coletivo e com as demandas dos alunos né tinha uma demanda dos alunos, tinha uma, dos professores e a equipe do PIBID tinha outra demanda então isso é complexo assim." (transcrição do Colaborador 1, grifo dos pesquisadores).

Para García (1995), o pensamento coletivo é fundamental para a reflexão do docente diante de sua construção profissional, evitando assim o seu isolamento e buscando alternativas e constantes diálogos na carreira docente, como discussões de casos da escola, ensino e relação professor/aluno, o que se associa com Cunha (1998) ao salientar que é preciso mexer com a criatividade e a curiosidade do aluno, utilizando métodos que ultrapassem crenças e o senso comum. Para Leal (2005) aquele que não planeja algo, seja uma aula ou o que fazer da vida, está em plena alienação, pois já aceitou tudo como está, ou até mesmo já robotizou suas tarefas. Sendo assim, não há criticidade sem planejamento.

\subsection{PIBID e contexto escolar}

Após a experiência do programa de iniciação à docência, 66\% dos ex-bolsistas veem a escola como um ambiente mais agradável, fato esse que corrobora o achado de Silva (2012) ao sinalizar que a maioria teve "uma melhoria na visão do ambiente escolar" (p. 16).

Atualmente, $85 \%$ dos ex-bolsistas conseguem desenvolver algo que aprendeu durante a participação do PIBID em suas experiências de trabalho. Para Tardif (2002) é o saber experiencial, aquele que advém através das representações sociais e é fundamental para a formação docente, no sentido de "experienciar" o contexto escolar. Entre os exemplos citados: "Ser mais crítica, o diálogo com as diferentes pessoas, saber que cada pessoa tem suas individualidades e portanto, o respeito em relação a isso." (Colaborador 5, grifo dos pesquisadores).

Nota-se aqui aspectos de aprendizagem quanto à criticidade, respeito e pensamento no planejamento de aulas, todos esses vivenciados e proporcionados pelo PIBID e que os ex-bolsistas carregam junto consigo mesmo após a sua participação. 
Para todos os ex-bolsistas que responderam o questionário eletrônico, o PIBID teve uma importância muito significativa no incentivo da sua formação em nível superior para a Educação Básica, para a contribuição do magistério, para um aumento da formação inicial na licenciatura, para a inserção no cotidiano escolar e para a articulação entre teoria/prática. Aqui nota-se que todos os objetivos do PIBID (CAPES, 2008) foram alcançados e incentivados para esses ex-bolsistas.

$\mathrm{Na}$ fala do grupo de discussão e da entrevista há comparações sobre o impacto do PIBID na formação dos mesmos: "No PIBID eu me vi como professora foi onde eu tive... não tinha nenhuma experiência e tive no PIBID e ali eu disse eu quero ser professora eu quero trabalhar em escola pública... No PIBID eu consegui saber o que queria fazer" (transcrição Colaborador 4).

O PIBID, nesse sentido, vai ao encontro de García (1995) que cita o choque de realidade do contexto escolar irá refletir pelo resto da carreira profissional do docente. Pode-se perceber então que o PIBID antecipa esse choque de realidade de uma forma mais confortável através da fala dos ex-bolsistas, pois a integração que o Programa causa no sentido de bolsista com outros bolsistas, professor(a) titular (supervisora) e professor Coordenador (IES) faz com que ocorra uma troca de experiências em grupo, o que diminui a sensação de algo, exclusivamente, do professor diante a sala de aula, o que vai ao encontro a Zeichner (1995), ao citar que há uma ausência curricular entre universidade e escola e isso se torna um dos grandes obstáculos à aprendizagem do professor desde a década de 90, mas que ainda está presente e é citado pela ex-bolsista:

''...o PIBID é muito bacana e deveria ser ampliado assim por todas as pessoas que vão se formar e passar, no início, um ano no PIBID, é o que eu penso...." (transcrição Colaborador 4, grifo dos pesquisadores), "a prática do PIBID eu acho que a gente deveria ter mais eu acho que até a nível da instituição mesmo..." (transcrição Colaborador 4). "a UNISINOS deveria ter algum projeto para entrar na realidade escolar mesmo..." (transcrição Colaborador 4, grifo dos pesquisadores).

A importância do Programa para a formação docente pode ser verificada na fala do participante do grupo de discussão ao indicar a participação dos acadêmicos em Licenciatura: '...não passar pelo curso sem ao menos tentar passar pelo PIBID." (transcrição Colaborador 1).

Nota-se a partir das falas tanto do grupo de discussão como na entrevista que o PIBID proporcionou novas experiências aos bolsistas na sua formação docente. Para Tardif (2002) os saberes do professor dependem do contexto social que o mesmo está inserido. Ou seja, o PIBID influencia no modo de agir e pensar no bolsista, pois o mesmo está dentro do contexto do Programa que vincula e insere-se em um ambiente escolar. $\mathrm{O}$ autor cita quatro fenômenos para isso: a universidade, experiências sociais, escola e seus aspectos e o próprio ambiente de trabalho (ensino). Nesse sentido, o PIBID encaixa-se nesses quatro universos, pois tem sua parte juntamente com a universidade em reuniões com professores do Ensino Superior, no sentido de ser uma experiência 
social dentro da escola que visa os seus aspectos de rotina e o próprio ensino aos alunos que serão o propósito da profissão de ser professor.

\section{7 'Levar o PIBID para a vida"}

O PIBID possibilitou aos ex-bolsistas o auxílio em aspectos da vida e não necessariamente só acadêmicos, mas também saberes experienciais (TARDIF, 2002), fato que é encontrado nas respostas do questionário eletrônico, tais como a visão sobre a escola e seus problemas (93\%), uma maior autoconfiança (66\%) e desinibição em falar em público (60\%), sendo o primeiro e o terceiro aspectos também achados por Silva (2012). A única diferença entre os resultados encontrados no presente estudo e nos achados de Silva (2012) foi que o diálogo com pessoas diferentes foi um dos mais citados pelos bolsistas e que no presente estudo difere-se pela perda de inibição ao falar em público.

O PIBID proporcionou um auxílio na escrita para os ex-bolsistas, pois o Programa dá a oportunidade aos bolsistas de participação de eventos, congressos e criação de artigos sobre o mesmo em trabalhos em grupo:

'... a gente teve que escrever artigos... isso acho que ajudou muito na minha trajetória acadêmica até para quando eu cheguei no meu Trabalho de Conclusão de Curso eu já tinha esse hábito de escrever artigos, isso me ajudou bastante..." (transcrição Colaborador 2), "...criar esse hábito de escrever, registrar essas coisas... muda a postura, a forma como tu enfrenta o modo de assistir uma aula..." (transcrição Colaborador 3), "pra mim o PIBID proporcionou muitas experiências né tanto na escola e na sala de aula como a gente falou na escrita para apresentar trabalho..." (transcrição Colaborador 2).

$\mathrm{Na}$ fala da ex-bolsista entrevistada, é visível a influência do PIBID no sentido de refletir sobre o presente: "....a questão de não ser conformada com a situação... a gente leva isso para a vida..." (transcrição Colaborador 4, grifo dos pesquisadores).

A reflexão na ação é fundamental para a formação de um docente prático autônomo, que pensa e repensa constantemente na sua ação quanto educador, fato esse discorrido pela entrevistada e possibilitado pela vivência no PIBID (SHÖN, 1995: GÓMEZ 1995).

\section{CONCLUSÃO}

O PIBID foi implantado com o intuito de melhorar a formação de docentes (CAPES, 2008), com uma integração visível entre Ensino Superior, Educação Básica e acadêmicos, formando assim tanto uma formação inicial quanto continuada, o que contribui para docentes em formação e já atuantes, pois o docente necessita racionalizar 
sobre sua própria prática diante da realidade social, vivências, sua própria vida e experiências na área escolar (TARDIF, 2002).

Ao analisar o questionário eletrônico, a entrevista e o grupo de discussão, é possível dizer que o PIBID, enquanto uma política educacional do governo com menos de dez anos de existência produz impactos positivos na formação de docentes, tais como oportunizar a experiência no contexto escolar como eixo central da formação docente; reflexões práticas onde há um pensamento sobre erros e acertos com a procura de aprimorar a tomada de decisões durante as aulas; colaborar com o planejamento coletivo e diálogos pedagógicos que evitam o isolamento profissional, pois o exercício da formação docente deve ser solidário e não solitário; antecipar o "choque de realidade" de uma forma mais confortável, pois há uma interação no Programa entre bolsistas, professora titular (supervisora) e professor (Coordenador e Professor do Ensino Superior), fazendo com que ocorra uma troca de experiências em grupo; influência no modo de agir e pensar no bolsista, pois o mesmo está dentro do contexto do Programa que vincula e se insere em um ambiente escolar; aumento da autoconfiança; desinibição em falar em público; integração possibilita a contextualização da escola e de seus problemas; permite a e interação com os alunos; causa reflexões constantes sobre o ensinar; pensar em grupo; permite a articulação teoria e prática; ocasiona experiências não só profissionais, mas também para a vida pós PIBID.

Como o programa é contemporâneo e de suma importância para a formação de docentes, há uma grande demanda de estudos futuros sobre o Programa, tais como os impactos do PIBID nos alunos, em professores titulares das escolas com o Programa ou até mesmo com os coordenadores das IES participantes. Também uma possibilidade de verificação de estudo é aprofundar os motivos da baixa atuação no ambiente escolar por ex-bolsistas do PIBID, como nos resultados encontrados no presente estudo.

\section{REFERENCIAS}

BARDIN, Laurence. Análise de Conteúdo. Lisboa: Edições. 1977

BAUER, Martin W.; GASKELL, George. Qualidade, quantidade e interesses do conhecimento. Petrópolis: Vozes, 2005.

BERKEMBROCK, I. T. M; Educação Superior e Educação Básica: Uma Análise do Perfil Dos Egressos Do Programa Institucional de Bolsas De Iniciação à Docência (PIBID). 37a Reunião Nacional da ANPEd - 04 a 08 de outubro de 2015, UFSC - Florianópolis. 7 p. Disponível em: <http://www.anped.org.br/sites/default/files/poster-gt11-4005.pdf>. Acesso em 26 de abr. de 2017.

BRASIL. Decreto Federal no 7219, de 24 de junho de 2010. Dispõe sobre o Programa Institucional de Bolsa de Iniciação à Docência - PIBID. 
BRASIL. Lei n 9.394, de 20 de dezembro de 1996. Estabelece as diretrizes e bases da educação nacional. Brasília, 1996. Disponível em: <http://portal.mec.gov.br/seesp/arquivos/ pdf/lei9394_ldbn1.pdf>. Acesso em: 7 de abr. 2017.

CARVALHO, M. R.; QUEIRES, L. C. Contribuições do Programa Institucional de Bolsa de Iniciação à Docência - PIBID para a Formação Docente nos Cursos de Licenciatura em Biologia: Estudo de Caso. Revista da SBEnBio. n 9. 2016.

CARVALHO, M. R; O Programa Institucional de Bolsa de Iniciação Docência - PIBID e suas Contribuições para a Formação Docente em Cursos de Licenciatura. Anais do Congresso Nordestino de Biólogos - Vol. 6: Congrebio 2016.

CENTRO DE APERFEIÇOAMENTO PESSOAL DE NÍVEL SUPERIOR. PIBID: Programa Institucional de Bolsa de Iniciação à Docência. CAPES, 2008. Disponível em <http://www.capes.gov.br/educacao-basica/capespibid/pibid> Acesso em 24 de abr. de 2017.

CRESWELL, John W. Projeto de pesquisa: método qualitativo, quantitativo e misto. Porto Alegre: Artmed, 2007.

CUNHA, Maria Isabel. O Professor Universitário na transição de Paradigmas. 1ª ed. 1998.

FREIRE, Paulo; Pedagogia da Autonomia: saberes necessários à Prática Educativa. Ano da digitalização: 2002. 92 p. Acesso em: 5 abr. 2017. Disponível em: <www.sabotagem.revolt. org>.

FREIRE, Paulo; SHOR, Ira. Medo e ousadia: o cotidiano do professor. Trad.: Adriana Lopes. 2 ed. Rio de Janeiro: Paz e Terra, 1986.

GARCÍA, Carlos Marcelo. A Formação de Professores: novas perspectivas baseadas na investigação sobre o pensamento do professor. In. NÓVOA, Antônio (ORG). Os professores e a sua formação. 2 ed. Lisboa: Dom Quixote, 1995. p. 51 - 72

GATTI, B. A. et al; Um Estudo avaliativo do Programa Institucional de Bolsa de Iniciação a Docência (PIBID). São Paulo: Fundação Carlos Chagas/SEP, 2014.

GAYA, Adroaldo. Ciências do Movimento Humano: Introdução à Metodologia de Pesquisa. Porto Alegre: Artmed, 2008. 304 p.

GÓMEZ, Angel Perez; O Pensamento Prático do Professor - A Formação do Professor como Profissional reflexivo. In. NÓVOA, Antônio (ORG). Os professores e a sua formação. 2 ed. Lisboa: Dom Quixote, 1995. p. 93114.

IBGE - Instituto Brasileiro de Geografia e Estatística. Panorama Rio Grande do Sul. 2010. Acesso em 30 out. 2017. Disponível em: <https://cidades.ibge.gov.br/brasil/rs/panorama>.

INEP - Instituto Nacional de Estudos e Pesquisas Educacionais Anísio Teixeira. Notas Estatísticas Censo Escolar 2016. Brasília: 2017. Acesso em 31 out. 2017. Disponível em: <http://download.inep.gov.br/educacao_basica/censo_escolar/notas_estatisticas/2017/notas_ estatisticas_censo_escolar_da_educacao_basica_2016.pdf>

LAKATOS E. M; MARCONI M. A.; Fundamentos da Metodologia Científica. São Paulo: Atlas. 2003. 
LEAL, Regina Barros. Planejamento de ensino: peculiaridades significativas. Rev.

Iberoamericana de Educación. 2005. Acesso em 13 ago. 2017 disponível em <http://rieoei. org/1106.htm>

MACHADO, Laêda. Representações sociais, educação e formação docente: tendências e pesquisas na IV Jornada Internacional. Rev. Educação em Foco. 2008. Acesso em 31 out. 2017. Disponível em: <http://www.fundaj.gov.br/geral/educacao_foco/ representantessociaislaedamachado.pdf $>$.

MEC. Planejando a Próxima Década: conhecendo as 20 Metas do Plano Nacional da Educação. 2014. 63 p. Acesso em 31 out. 2017. Disponível em: <http://pne.mec.gov.br/ images/pdf/pne_conhecendo_20_metas.pdf>.

MOSCOVICI, S. A representação social da psicanálise. Tradução de Álvaro Cabral. Rio de Janeiro: Zahar. 1978. 291p

NÓVOA, Antônio (Coord.). Os professores e a sua formação. 2 ed. Lisboa: Dom Quixote, 1995.

RAUSCH, R. B.; FRANTZ, M. J. Contribuições do PIBID à Formação Inicial de Professores na Compreensão de Licenciandos Bolsistas. Atos de Pesquisa em Educação PPGE/ME. v. 8 n. 2. p. 620-641. 2013

RUIZ, A. I. Formação continuada em áreas específicas. A proposta do sistema nacional público. Retratos da Escola, Brasília, v. 2, n. 2/3, p. 149-160, jan./dez. 2008.

SANTOS, Tania Steren; Do artesanato intelectual ao contexto virtual: ferramentas metodológicas para a pesquisa social. Sociologias. Porto Alegre, ano 11, no 21, p. 120156, jan/jun/2009. Acesso em: 15 set 2017. Disponível em: <http://www.scielo.br/scielo. php?pid=S1517-45222009000200007\&script=sci_abstract\&tlng=pt>

SHÖN, Donald. Formar Professores como Profissionais Reflexivos. In. NÓVOA, Antônio (ORG). Os professores e a sua formação. 2 ed. Lisboa: Dom Quixote, 1995. p. 77 - 92.

SILVA, Michele Silveira. O Programa De Bolsas De Iniciação à Docência (PIBID) e a Carreira Docente Em Ciências Biológicas. UFRGS: 2012. Disponível em: <http://www. lume.ufrgs.br/handle/10183/72342> Acesso em 20 abr. 2017

TARDIF, Maurice. Saberes docentes e formação profissional. Petrópolis, RJ: Vozes. 2002.

ZEICHNER, Ken. Novos Caminhos para o Practicum: uma perspectiva para os anos 90. In. NÓVOA, Antônio (ORG). Os professores e a sua formação. 2 ed. Lisboa: Dom Quixote, 1995. p. 115 - 138. 